\title{
Different Types of Eco-Friendly Fertilizers: An Overview
}

\author{
Goutam Hazra $^{1^{*}}$ \\ ${ }^{1}$ Department of Chemistry, Kalna College, Kalna-713409, India \\ *Goutam Hazra, E-mail: hazragoutam1980@rediffmail.com \\ "A nation that destroys its soils destroys itself. Forests are the lungs of our land, purifying the air and \\ giving fresh strength to our people"-Franklin D. Roosevelt
}

\begin{abstract}
In this paper author trying to give the attention on eco-friendly fertilizers rather than the commercially available inorganic fertilizers. Here different types of eco-friendly fertilizers, i.e., organic fertilizers and some types of slow or Controlled Release Fertilizers (CRF) including Glass Fertilizer were described with their nutrients release mechanism. The environmental hazardous effects, i.e., disadvantages of different common commercially available fertilizers and advantages of organic fertilizer and controlled release fertilizers including Glass Fertilizer over common inorganic fertilizers properly explained here. There are numerous crops and plants which have different growing habits and nutrient requirements. The fertilizers help us in understanding the precise needs and requirements of the plants fulfilling which maximum production can be reached. The blended mixtures of measured quantities of the nutrients enable the plants to get potential nutrition and help them to hasten growth and yield more than their usual capacity. The fertilizers are highly soluble and do not take much time to get dissolved in the soil and reach the plant in no time. However, it happens only in the case of chemical fertilizers and organic fertilizers take time to be dissolved. Moreover, agricultural fertilizers are a combination of hazardous and beneficial fertilizers. Organic fertilizers are not as harmful as the inorganic ones however the former takes more time than the latter top reach the roots of the concerned plants. Excessive fertilization does encourage great yields however also invites air, water and soil pollution. Therefore, it is very necessary to use fertilizers in limited quantities and if possible then organic and inorganic should be used simultaneously to counterattack the miscellaneous soil hazards.
\end{abstract}

\section{Keywords}

fertilizer, Eco-friendly, plant-nutrients, microorganisms, bio-degradable, green-manure, controlled-released

\section{Introduction}

We are losing about 1,000 tons of topsoil every second and year after year arable land shrinks by 20,000 hectares (Hazra, 2014). Erosion alone has made a billion hectares of soil unusable for agriculture. Plants serve as the major source of feed for livestock. Nutrients required for maintenance and production are provided by various plants and plant derived feeds along with small amounts from 
non-plant sources. The major constituents of plants are water, carbohydrates, protein, fat, minerals and vitamins. Both plants and animals contain these nutrients, but the relative proportions vary more in plants (Prasad, 2009; Roy et al., 2006). Today productivity has been increased by a major proportion and the entire credit goes to fertilizers. Fertilizers are a superior and advanced means to promote and enhance productivity. All the fertilizers have been categorized into several types depending on their constituents, strength and various other features. However each fertilizer contains adequate amounts of the needed chemicals, minerals and elements to ensure a healthy and fast growth. Though the fertilizers are essential for all plants or crops but there have also it adverse effects (Prasad, 2009; Camargo et al., 2006). The excess of chemical fertilizers destroy the soil fertility as well as bring back different types of environmental pollutions (Camargo et al., 2006; Hazra et al., 2014). So in the agricultural and others purposes there have adequate use of eco-friendly fertilizers which enhance productivity but have no adverse effect for nature.

\section{What is a Fertilizer?}

The chemical composition of various essential minerals and elements meant for the regular as well as hastened growth and nourishment of all plants is termed as fertilizer. As these fertilizers have been used invariably to promote and enhance the productivity of commercial crops, therefore they are called agricultural fertilizers. Fertilizers enhance the richness of the soil and nourish it with required nutrients. By enriching the soil, fertilizers also increase the productivity of the crops. Fertilizers are the nutrient filled sources which nourish the plants with essential nutrients and soil acts as a medium between the crops and the fertilizers (Bokhtiar et al., 2005). A substance (such as manure or a special chemical) that is added to soil to help the growth of plants (Merriam-Webster.html, 2016).

\section{Types of Agricultural Fertilizers}

As it has been explained that fertilizers are composition of one or various chemical compounds or nutrients therefore depending on the constituent compounds and nutrients release mechanism, the agricultural fertilizers have been categorized into following categories:

a) Organic agricultural fertilizer

Organic fertilizers are those fertilizers which are manufactured using organic substances which are bio-degradable, i.e. Organic fertilizers are naturally occurring fertilizers and nutrient enhancers of the soil (Bokhtiar et al., 2005). Therefore every substance that occurs naturally and is easily bio-degradable is organic and if this organic material enhances the richness of the soil, it is termed as organic fertilizer. These organic substances are further decomposed and broken into smaller and soluble particles by numerous microorganisms. After being turned into soluble and simpler compounds, these fertilizers are taken in by the roots. Manure, slurry, worm castings, peat, seaweed, sewage, and guano are the naturally occurring Green manure and compost, blood meal, bone meal and seaweed extracts, etc. are manufactured organic fertilizers. Crops are also grown to add nutrients to the soil. Today what each 
farmer is looking forward to be a proper solution to the agricultural problems without compromising on the yields. It is a universally acknowledged fact that organic fertilization methods are more environmental friendly and fetch slower but steady results. Today when the world is advancing so fast in every aspect, how can the lives supporting area can be ignored? Today the use of fertilizers is one of the greatest innovations of the agricultural revolution.

b) Inorganic agricultural fertilizer

Those fertilizers which are constituted by inorganic chemical substances are referred to as inorganic agricultural fertilizers, i.e., granular triple superphosphate, potassium chloride, urea, anhydrous ammonia, etc. These fertilizers are usually non-biodegradable. And these are further divided into various categories based on their constituents and methods of preparations. These fertilizers are also called artificial or synthesized fertilizers as they are manufactured in the factories using latest technologies. The artificial manufacturing processes render these fertilizers a rough touch and propel them to be sturdy and highly per-formative (Liu et al., 2007).

c) Advantages of chemical inorganic fertilizer

1) Readily available: as the most common form used, it is found everywhere.

2) Formula variety: it is easy for chemical companies to vary the elements to produce blends for different seasons and for specific plants.

3) Fast acting. Usually see results within 1-2 weeks if the formula used is appropriate for the season.

4) Inexpensive: typically, except for the better quality blends that have controlled release pellets.

5) Ease of application: using fertilizer spreaders. Rates and settings are usually calculated and displayed on bag.

6) Multiple forms: available in pellets, granules, liquid, tablets, spikes and slow-release, to suit every preference.

7) They are quite high in nutrient content; only relatively small amounts are required for crop growth (Madani et al., 2011; Chen, 2006).

\subsection{Macronutrients Fertilizers}

The concentration of each fertilizer in the dry base determines their strength and also their constituent elements. There are six main and most prominent elements which play a vital role in the growth of the plants. Nitrogen, phosphorus, and potassium are primary macro-nutrients. These macro-nutrients are very essential for the proper and anti retarding growth of any plant and further these nutrients enhance the yields by great differences (Roy et al., 2006). Calcium, magnesium, and sulphur come under the category of secondary macro-nutrients. Although all these nutrients are required by the plants in almost similar quantities however their availability marks the difference (Hazra et al., 2014; Pansu et al., 2006).

\subsection{Micronutrients Fertilizers}

Plants also need certain nutrients in little but essential quantities and absence of these elements might hamper the growth in an effective manner. The plant growth can be retarded and can show a lasting 
impact on the yields as well (Roy et al., 2006; Pansu et al., 2006). However, the micro-nutrient fertilizers are meant to serve the lessened but necessary needs of the plants and therefore these fertilizers are aimed at providing little portions of nutrients like iron, manganese, boron, copper, molybdenum, nickel, chlorine and zinc (Roy et al., 2006; Hazra et al., 2014; Kabata-Pendias et al., 1993). The concentrations in which these elements are needed range vividly from 5-100 ppm. The essential plant nutrients (macro and micro), their forms taken up and their typical concentration in plants are shown in the Table 1.

Table 1. Essential Plant Nutrients, Forms Taken up and Their Typical Concentration in Plants (Roy et al., 2006)

\begin{tabular}{|c|c|c|c|}
\hline Nutrient (symbol) & Essentiality established by & Forms & $\begin{array}{l}\text { Typical concentration } \\
\text { in plant dry matter }\end{array}$ \\
\hline \multicolumn{4}{|l|}{ Macronutrients } \\
\hline Nitrogen $(\mathrm{N})$ & De Saussure (1804) & $\mathrm{NH}_{4}^{+}, \mathrm{NO}_{3}^{-}$ & $1.5 \%$ \\
\hline Phosphorus $\left(\mathrm{P}, \mathrm{P}_{2} \mathrm{O}_{5}\right)$ & Sprengel (1839) & $\mathrm{H}_{2} \mathrm{PO}_{4}^{-}, \mathrm{HPO}_{4}{ }^{2-}$ & $0.1-0.4 \%$ \\
\hline Potassium $\left(\mathrm{K}, \mathrm{K}_{2} \mathrm{O}\right)$ & Sprengel (1839) & $\mathrm{K}^{+}$ & $1-5 \%$ \\
\hline Sulphur (S) & Salm-Horstmann (1851) & $\mathrm{SO}_{4}^{2-}$ & $0.1-0.4 \%$ \\
\hline Calcium (Ca) & Sprengel (1839) & $\mathrm{Ca}^{2+}$ & $0.2-1.0 \%$ \\
\hline Magnesium (Mg) & Sprengel (1839) & $\mathrm{Mg}^{2+}$ & $0.1-0.4 \%$ \\
\hline \multicolumn{4}{|l|}{ Micronutrients } \\
\hline Boron (B) & Warington (1923) & $\mathrm{H}_{3} \mathrm{BO}_{3}, \mathrm{H}_{2} \mathrm{BO}_{3}^{-}$ & $6-60 \mu \mathrm{g} / \mathrm{g}(\mathrm{ppm})$ \\
\hline Iron $(\mathrm{Fe})$ & Gris (1943) & $\mathrm{Fe}^{2+}$ & $50-250 . \mu \mathrm{g} / \mathrm{g}(\mathrm{ppm})$ \\
\hline Manganese (Mn) & McHargue (1922) & $\mathrm{Mn}^{2+}$ & $20-500 . \mu \mathrm{g} / \mathrm{g}(\mathrm{ppm})$ \\
\hline Copper $(\mathrm{Cu})$ & Sommer, Lipman (1931) & $\mathrm{Cu}^{+}, \mathrm{Cu}^{2+}$ & $5-20 . \mu \mathrm{g} / \mathrm{g}(\mathrm{ppm})$ \\
\hline Zinc (Zn) & Sommer & $\mathrm{Zn}^{2+}$ & $21-150 . \mu \mathrm{g} / \mathrm{g}$ \\
\hline
\end{tabular}

\section{Fertilizer and Environment}

The environment protection is very important in an industrial world. Using of fertilizers in agriculture can be very useful for a food production, but on the other hand it may be very dangerous for environment. Therefore only necessary amount of fertilizers can be used for successful vegetation. It means that we must use fertilizers, which dissolved it as is nutrient requirement of plants. In this case it is not a contamination hazard for environment. The main elements for successful plant vegetation are $\mathrm{K}$, $\mathrm{Ca}, \mathrm{Mg}, \mathrm{P}, \mathrm{N}, \mathrm{Fe}$ and $\mathrm{Zn}$. Many types of fertilizers supply these elements, but the velocity of dissolution of fertilizer in an agricultural land is greater than requirement of plants (Camargo et al., 2007; Kabata-Pendias et al., 1993; WHO, 2006). The biggest issue facing the use of chemical fertilizers is groundwater contamination. Nitrogen fertilizers break down into nitrates and travel easily through the 
soil. Because it is water soluble and can remain in groundwater for decades, the addition of more nitrogen over the years has an accumulative effect. At the University of Wisconsin, Madison, they discovered the effects of chemical fertilizers are compounded when mixed with a single pesticide. They discovered altered immune, endocrine and nervous system functions in mice, as well as influence on children's and foetus's developing neurological, endocrine and immune systems. These influences "portend change in ability to learn and in patterns of aggression" (U.S. Environmental Protection Agency Ground Water and Drinking Water, 2006). One popular fertilizer, urea, produces ammonia emanation, contributes to acid rain, groundwater contamination and ozone depletion due to release of nitrous oxide by denitrification process. With its increased use and projections of future use, this problem may increase several fold in the coming decades. Groundwater contamination has been linked to gastric cancer, goitre, birth malformations and hypertension; testicular cancer and stomach cancer. Excessive air- and water-borne nitrogen from fertilizers may cause respiratory ailments, cardiac disease and several cancers, as well as can "inhibit crop growth, increase allergenic pollen production, and potentially affect the dynamics of several vector-borne diseases, including West Nile virus, malaria and cholera". Perhaps one of the scariest effects of chemical fertilizers is something called methe mo globinemia. In infants it is alternatively known as Blue Baby Syndrome. The risk most often occurs when infants are given formula reconstituted with nitrate contaminated water (Alloway et al., 1999; Basta et al., 2001; Raicevic et al., 2005). The condition causes a decrease in oxygen in the blood and results in a blue-grey skin color, causes lethargy and/or irritability and can lead to coma or death. I've been unable to find whether the same risk exists for breastfeeding babies whose mothers drank contaminated water (Camargo et al., 2006; U.S. Environmental Protection Agency Ground Water and Drinking Water, 2006). Nitrogen groundwater contamination also contributes to marine "dead zones". The increase in the water-soluble nitrates creates an influx of plant-life, which eats up oxygen and starves out fish and crustaceans. This has an impact not only on the aquatic ecosystem, but on local societies who depend on food sourced from those areas. And then there is the highly questionable use of raw sewer sludge as a fertilizer. Yes, you heard me right. In some countries, raw, uncomposted and untreated human waste is applied directly to crops and soil, a practice known as "night soil" since it's typically applied at night. The risk of disease is obvious and high and this practice should never be confused with "humanure", a long, highly involved process of decomposing human waste into a safe resource.

\section{Naturally Occurring Organic Fertilizers}

It includes animal manure, slurry waste, peat, seaweeds, sewage, guano waste and other bio-degradable wastes. Mine rock phosphate, sulphate, potash and limestone also fall under the same category. Decomposing crops also make up for a naturally occurring organic fertilizers (Bokhtiar et al., 2005).

Manure: The organic waste of animals is termed as manure when it gets decomposed by the ongoing process of bacteria and fungi. This decomposed matter called manure is then used in agriculture to 
enhance and promote productivity of soil and thus revolutionize the yields.

Slurry waste: Scientifically it is a thick blend of solids in any liquid and when talking about agricultural slurry it has to be any house or animal waste material well blended with water to inculcate soil fertility. It is prepared through a long term process of collecting the waste material in a huge container or tanks and then transported to the agricultural fields in the similar liquid form. It is in liquid form; therefore it gets dissolved easily and mixes well with the soil which leads to nutrition of soil.

Worm Castings: It is also referred to as by different names such as vermin compost, worm compost, worm humus, etc. It is the end product of anything that is resulted after the break-down of any organic material or waste by the worms, insects or earthworms. It is highly rich in nutrients and proves to be a worthy soil conditioner.

\section{Manufactured Organic Fertilizers}

The fertilizers which are manufactured by decomposition of natural waste material are termed as manufactured organic fertilizers. Compost, blood meal, bone meal and sea weed extracts.

Compost: Also called as Brown manure, it is the end product of the decomposition of the organically waste material. It is a process which is carried on by numerous bacteria, fungi and other little organisms. Used in landscaping, horticulture, and to prevent soil erosion, compost is an effective solution to soil troubles.

Bloodmeal: It is a nitrogenous fertilizer which is made of dried powdered blood. Highly soluble mixture it can easily be taken in by the soil and it is a huge storehouse of ammonia and other nitrogenous elements. After being mixed with water, it can be used as a liquid fertilizer. It can also be sprayed in garden as a animal and insects deterrent.

Bone meal: As the name suggests, bone meal is a crude mixture of crushed and powdered.

bones: It works effectively as a slow source of nutrients which keeps on supplying the essential nutrients at equal intervals. It is a great source of phosphorous.

\section{Advantages of Organic Fertilizers}

The organic humus registers a very important role in the soil nourishment. It mobilizes the existing soil nutrients and enables them to reach the plants in equal and balanced quantities.

The nutrients are released at a slower speed which implies that the plants are not suffixed to pressurized growth but their natural capability is enhanced to a greater extent. This ensures safety of plants and lessened toxic levels in the plants.

Organic fertilizers retain a blanket like cover on the soil thus enabling it to recapture the moisture level and not let it out. Thus it also helps to recover the stress levels of the soil by maintaining its moisture content.

The organic fertilizers help to sophisticate the soil structure by nourishing it, enhancing its productivity and at the same time protecting it from being eroded away. Artificial and inorganic fertilizers have 
certain disadvantages as they have to be applied again and again. They become a necessity to the soil or else the productivity is hampered. They act as a drug for the soils as till the time the soils are fertilized they remain productive or else they die down. Eutrophication, nutrient pollution is caused due to extra application of the artificial fertilizers (Bokhtiar et al., 2005; Kaur et al., 2005).

Some advantage of the organic fertilizer

1) Better for the soil: provides organic matter essential for microorganisms. It is one of the building blocks for fertile soil rich in humus.

2) Nutrient release: slow and consistent at a natural rate that plants are able to use. No danger of over concentration of any element, since microbes must break down the material.

3) Trace minerals: typically present in a broad range, providing more balanced nutrition to the plant.

4) Won't burn: safe for all plants with no danger of burning due to salt concentration.

5) Long lasting: doesn't leach out since the organic matter binds to the soil particles where the roots have access to it.

6) Fewer applications required: once a healthy soil condition is reached, it is easier to maintain that level with less work.

7) Controlled growth: does not over-stimulate to exceptional growth which can cause problems and require more work.

8) Stronger plants and grass: greater resistance to disease and insect attacks (Chen, 2006).

9) Beneficial to environment. Won’t build up harmful residues or cause pollution due to run-off from irrigation or rain.

10) Encourages soil life. Microbes convert the organic matter to the form of nutrients that plants need. Earthworms feeding on organic materials aerate and loosen the soil (Young et al., 2003).

11) Specific formulas: adapt to any application by changing the ingredient blend. Pre-blended formulas or individual items allow flexibility for plant preferences or needs.

\section{Different Types of Eco-Friendly Fertilizers}

Biocompost: It is a kind of organic fertilizer, which is prepared from the waste of the sugar industry. The waste is decomposed using a number of human and plants friendly bacteria and Fungi. Biocompost consists of nitrogen, phosphate solubilizing bacteria and plenty of useful fungi like the decomposing fungi. This biofertilizer helps the farmers to increase soil fertility and thereby increase the yield of the crops.

Vermi Compost: It is also an organic fertilizer containing nitrogen phosphorus, potassium, sulphur, organic carbon, sulfur, hormones, enzymes, etc. If used over a period of time, the soil becomes extremely fertile and all the lost nutrients are restored back to the turf and the soil remains fertile. 


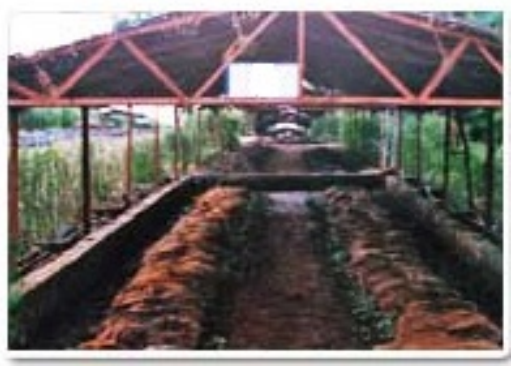

Figure 1. Preparation of Vermi Compost

Phospho: This is also a kind of bio-fertilizer, which releases insoluble phosphorous in the soil, making it more fertile.

Rhizo: It is a bacterial, which induces nitrogen fixing nodules on the roots of vegetables like peas, beans, etc., thereby, playing an important role in agriculture.

Azotobactor: Nitrogen plays an extremely important role in plant growth. Azotobactor improves the quantity of atmospheric nitrogen in the soil and makes it available to the plants. It also shields the roots from other pathogens existing in the soil.

Trichoderma: It is an eco-friendly fertilizer, which acts as a biocontrol agent and is hyper parasitic against different pathogens in the field.

Composter: A composter breaks down all organic substances like cattle waste, dead leaves, etc. present in the soil and thereby increases the productivity of the soil.

Tricho-Card: It is an effective bio-fertilizer, which is an effective destroyer of eggs of many rodents, which eat plants and leaves. It is effective when used for many plants namely sugarcane, cotton, brinjal, corn, jawar, paddy apple, etc.

\section{Various Types of Controlled Release Fertilizers}

In recent use there have different types of slow or controlled release fertilizers (Hazra, 2014; Prasad, 2009; Roy et al., 2006; Camargo et al., 2006; Hazra et al., 2014; Shaviv, 2005; Shaviv et al., 1993a, 1993b, 1995, 2003; Shoji, 2005) some of them are as follow:

\section{Sulfur Coated Urea (SCU)}

Sulfur Coated Compound Fertilizer

Resin Coated Fertilizer

Urea formaldehyde

Urease and Nitrification inhibitors

Tower Melt Spraying Granulation Compound Fertilizer

Urea Melt Spraying Granulation Compound Fertilizer

Chemically Modified Biomass Coating Urea for Controlled Released

Bulk Blend Fertilizer and

Glass fertilizer 


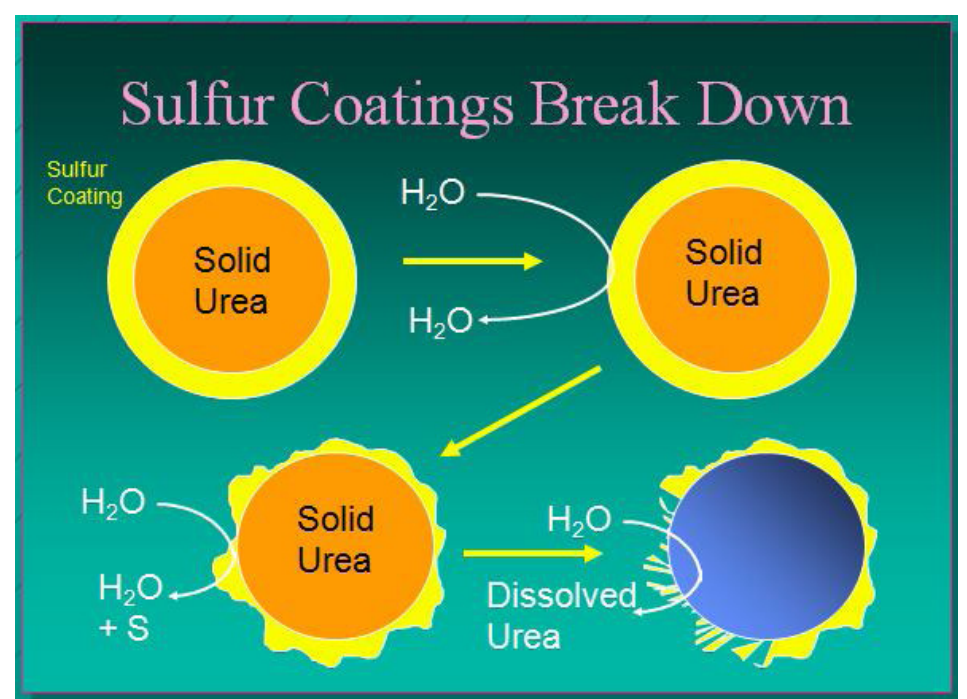

Figure 2. Schematic Picture of Sulphur Coating Break down of Sulphur Coated Urea (SUC) (Hazra, 2014; Hara, 2000)

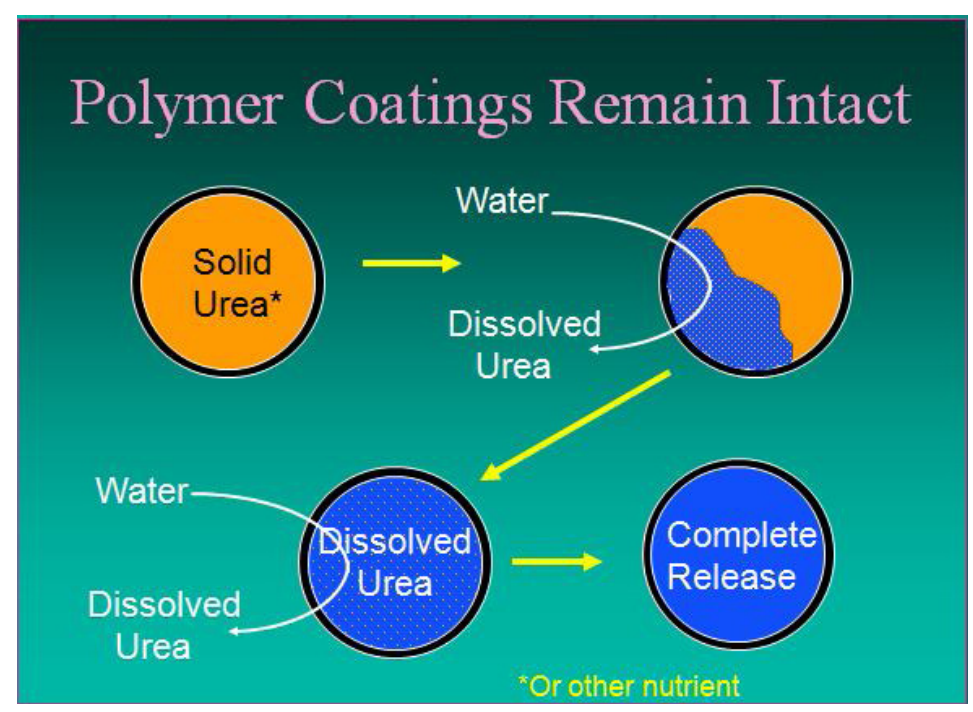

Figure 3. Schematic Picture of Polymer Coating Break down of Polymer Coated Urea (Hazra, 2014; Hara, 2000) 


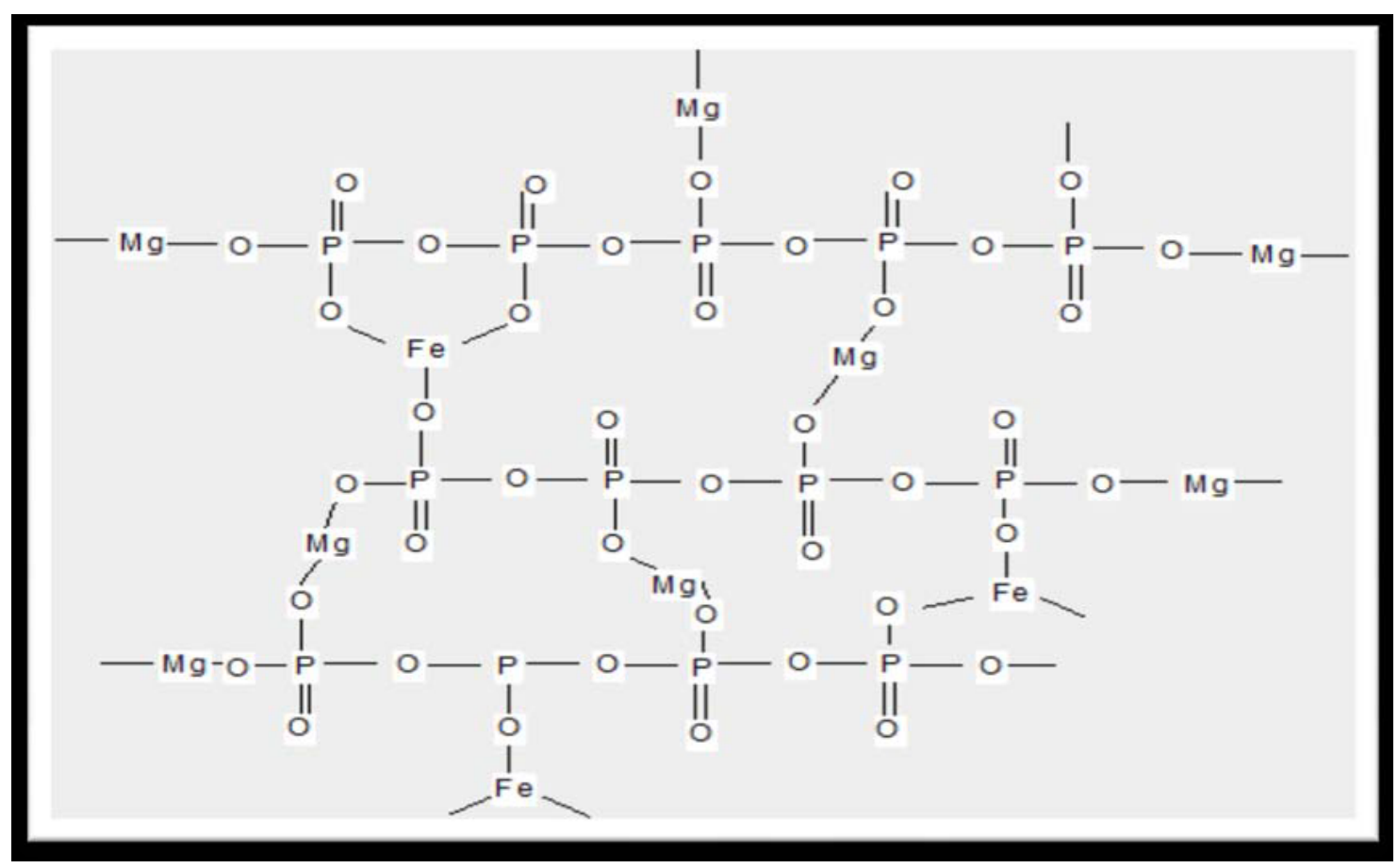

Figure 4. Typical Structure of a New Slow-Releasing Iron Fertilizer (Chandra et al., 2009)

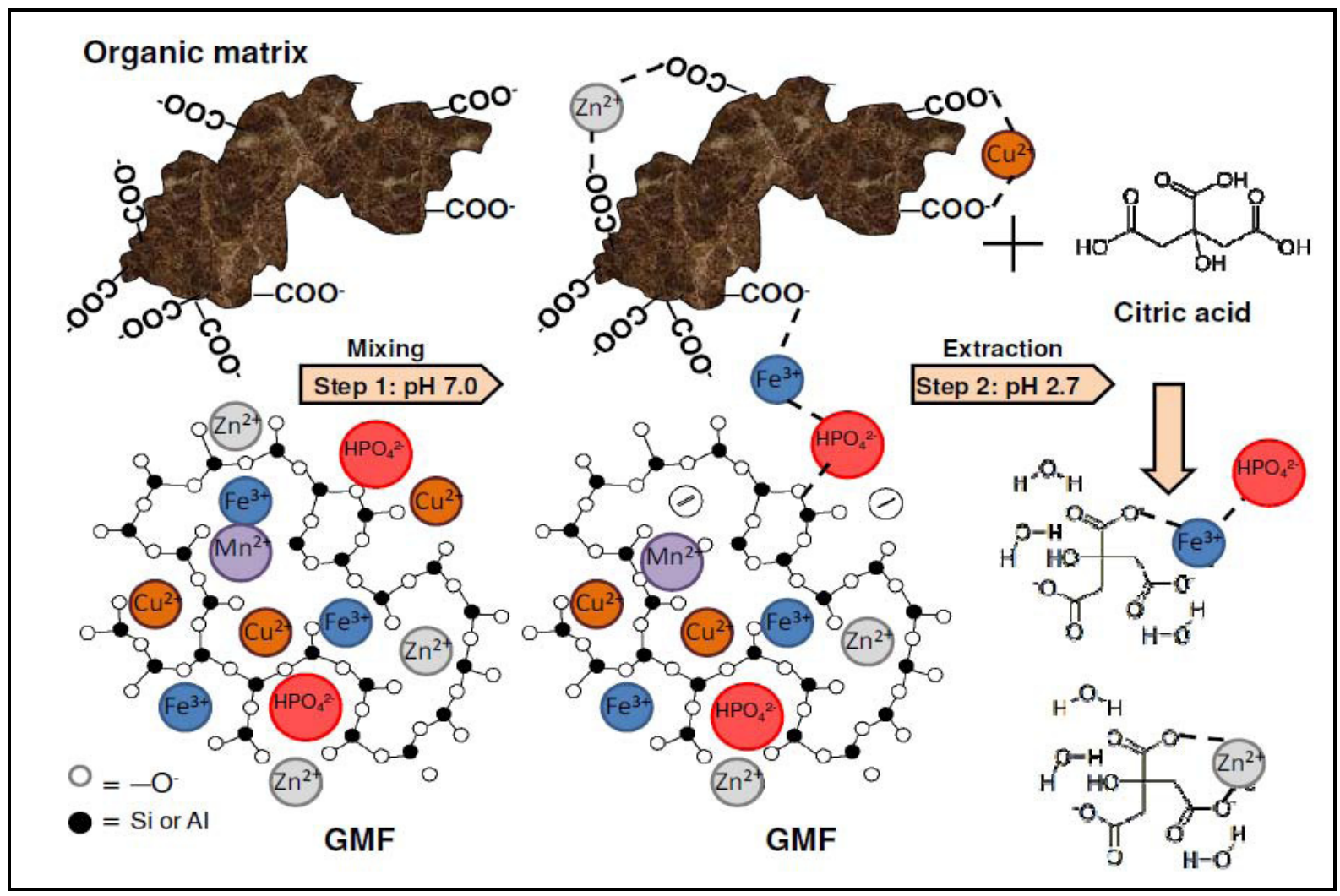

Figure 5. Schematic Binding Procedure of Glass Fertilizers' Nutrients with Soil Showing Its' Network Structure (Trinchera et al., 2011) 


\section{Advantages of the Controlled Release Fertilizers as well as Glass Fertilizer}

1) Decrease fertilizer application rate and save labour. Slow/controlled release fertilizer can produce the same yield with the rate $10-40 \%$ less than conventional fertilizer. Sometimes, only single application is required, which can reduce labour cost by 75\% (Hazra, 2014; Hazra et al., 2014; Trenkel, 2010).

2) Reduce environmental pollution caused by fertilizer. To increase fertilizer use efficiency with slow/controlled release technology equals to the increase in fertilizer production. The current urea production in China is approximately 20 million tonnes, if coated with sulfur, the nitrogen use efficiency can be improved by 20\% (Hazra, 2014; Prasad, 2009; Roy et al., 2006; Camargo et al., 2006; Hazra et al., 2014; Tachibana, 2007, 2008).

3) Each element contained in controlled release fertilizer has an effect to give a very high increase in the fertility of the soil; each nutrient of CRF is not water-soluble yet easily soluble in weak acidic content in the soil or generated by plant roots (Hazra, 2014; Prasad, 2009; Roy et al., 2006; Camargo et al., 2006; Hazra et al., 2014; Biagio et al., 2013).

4) The CRF neutralize toxic acids and toxic elements in the soil and from other fertilizers (Wacławska et al., 2011).

5) Glass fertilizer does not contain toxics substances, since it does not have an acidic sulphate or chloricradical, glass fertilizer does not cause acidity to the soil, toxic gas or hydro sulpharic that can destroy plant roots on rice-fields. Normally, the soil is poor in phosphate $\left(\mathrm{P}_{2} \mathrm{O}_{5}\right)$, therefore, $\mathrm{P}_{2} \mathrm{O}_{5}$ is necessarily to be added. $\mathrm{P}_{2} \mathrm{O}_{5}$ is the important constituents of plant root cells which assist the roots in growing strongly thus further improving the yield. The glass fertilizer is not water-soluble, it lies within the soil and continues providing necessary nutrients for the plants, meanwhile, other kinds of fertilizer are easily soluble in water, for example, super phosphate, and ammoniac sulphate can have immediate effects but are easily held by aluminum in the soil thus rapidly washed out. Plant roots still continue to dissolve $\mathrm{P}_{2} \mathrm{O}_{5}$ via immediate contact with glass fertilizer in the soil. This effect is very important to the type of soil originating from volcano ashes, wild soil and exhausted fields' poor in $\mathrm{P}_{2} \mathrm{O}_{5}$ (Hazra, 2013, 2014).

6) The glass fertilizer not only helps increase the fertility of the soil, suitable for many kinds of plant but also help prevent lack of magnesium and some other nutrients in the soil that support the plants' growth. $\mathrm{Mg}$ and $\mathrm{Ca}$ are much in the soil but due to long-term withering in acidic alum soil, the alkali effect is void, this frequently occur in tropical and subtropical zones (Hazra, 2014; Hazra et al., 2014).

$\mathrm{Mg}$ is very necessary for creating Chlorophyll in plant leaves, the main constituent of the plants. $\mathrm{Mg}$ plays an essential role in the production of protein and fat in plants. $\mathrm{Mg}$ improves the effect of phosphate, helping plants absorb the nutrients lying inside the soil and also participate in transporting $\mathrm{P}_{2} \mathrm{O}_{5}$ that has been absorbed in the tree-trunk. Fussed magnesium phosphate fertilizer can be seen as the most suitable one in tropical and subtropical zones poor in $\mathrm{P}_{2} \mathrm{O}_{5}$ (Sava et al., 2011). 


\section{Advantages of Using Bio-Fertilizers}

Bio-fertilizers are becoming a rage, considering the irreparable damage that the chemical fertilizers are causing to the soil. Some of the advantages associated with bio-fertilizers include:

1) The first and the most important advantage of using bio-fertilizers is that they are environment friendly, unlike chemical fertilizers that damage the environment.

2) They are comparatively low on cost inputs and are light on the pockets of the farmers.

3) Their use leads to soil enrichment and the quality of the soil improves with time.

4) Though they do not show immediate results, but the results shown over time are extremely spectacular.

5) Microorganisms convert complex organic material into simple compounds, so that the plant can easily take up the nutrients.

6) These fertilizers harness atmospheric nitrogen and make it directly available to the plants.

7) They increase the phosphorous content of the soil by solubilising and releasing unavailable phosphorous.

8) Bio-fertilizers improve root proliferation due to the release of growth promoting hormones.

9) They help in increasing the crop yield by $10-25 \%$.

\section{Disadvantages of Commercially Available Inorganic Chemical Fertilizers and Organic or Eco-Friendly Fertilizers}

\subsection{Disadvantages of Chemical Inorganic Fertilizers}

1) Water soluble in most forms. Since water releases the nutrients, it is not uncommon to lose one-third of the nutrients by leaching out of the soil before the plant can access them.

2) Short life span, unless using a controlled release form.

3) Doesn't build up the soil. The basic synthetic elements contribute nothing to enhance soil fertility.

4) May decrease soil fertility. Chemical nitrogen stimulates the growth of existing microorganisms, which then use up organic matter in the soil. Repeating this cycle regularly leaves soil depleted.

5) Excess growth can occur with some varieties or with surplus application. This results in more mowing or pruning, places stress on roots, causes heavier grass stains on clothes from lawns.

6) Danger with incorrect application. Potential of harm from excess, especially lawns getting coverage overlap.

7) Salt burn risk. Synthetic fertilizer is salt. Over application can result in negative effects such as leaching, pollution of water resources, destruction of micro-organisms and friendly insects, crop susceptibility to disease attack, acidification or alkalization of the soil or reduction in soil fertility—-thus causing irreparable damage to the overall system (Hazra et al., 2014; Chen, 2006).

8) Trace nutrients missing, in many synthetic blends. Excess of major nutrients can bind up other nutrients in the soil, making them unavailable to the plant.

9) Environmental problems occur with chemical run-off.

Published by SCHOLINK INC. 
10) Excess phosphorous can collect in the soil and cause pollution problems.

11) Nitrogen is volatile: is lost easily into the atmosphere when fertilizer is left on the ground and not watered into the soil. It is also lost from bags in storage, if not sealed properly.

12) Absorbs moisture easily in storage. This results in caking, or hard fertilizer, which is difficult or impossible to use.

13) Iron stains. When added to formula, it is water soluble and can leave rust stains on concrete if not handled correctly.

14) High energy consumption required to produce these products (http://www.garden-counselor-lawn-care.com/organic-vs-non-organic-fertilizer.html).

15) Eutrophication: Overgrowth of aquatic vegetation and degradation of water quality due to extra nitrogen accumulation.

16) Increased acidity: Many chemical fertilizers are composed of acids like sulphuric acid and hydrochloric acid and these acids decrease the soil's quality and heighten the acidity which further registers a bad impact on the plant growth.

a) Loss of bacteria: The natural nitrogen fixing bacteria, rhizobium suffers great blows from the excessive usage of chemical bacteria.

b) Certain plants are hampered due to excessive dozes of the chemical fertilizers so much so that they also tend to cease growing and yield fruits.

c) Synthetic fertilizers may be fast-acting but they come with a price (http://www.diffen.com/difference/Chemical_Fertilizer_vs_Organic_Fertilizer).

\subsection{Disadvantages of Organic Fertilizers}

1) Slow to release nutrients. Cooler soil temperatures are not as conducive to the release of elements. The nutrient release rate is too slow to meet crop requirements in a short time, hence some nutrient deficiency may occur (Chen, 2006).

2) Dependent on microorganisms in the soil to break down organic material. Soils depleted of these beneficial microbes further delay the results from organics.

3) More expensive than chemical fertilizer applied to equal square footage. Some retailers do not offer larger size bags that would make it more economical.

4) Application less convenient in some forms. Meal form, unlike pellets, is difficult to apply on large areas like lawns.

5) Residue in liquid forms: some, like fish concentrate, may not be finely strained, and clogging of sprayers can occur.

6) Pets may be attracted to certain natural fertilizers. Dogs may want to roll in it, dig, or get into the bag, especially with blood meal or bone meal.

7) Limited availability in some areas. All of the blends may not be offered, or the choice of individual ingredients may be limited, depending on locale.

8) Can attract bugs in storage if not protected in sealed containers (not paper bags). 
9) Animal manures that are not fully composted can cause problems when used directly as fresh fertilizer. Homemade natural fertilizers are not automatically a good idea (http://www.garden-counselor-lawn-care.com/organic-vs-non-organic-fertilizer.html).

Caution: The fertilizers are harmful therefore avoid any physical contact and tie your mouth with a clean cloth and wear gloves in case of applying it with hands. Inhalation or consumption might cause severe injuries, allergies and death also. However, organic fertilizer might work slower but they leave an everlasting impact on the soil texture and improve the water holding capacity of the soil regains its fertility and prevents soil erosion.

\section{Conclusions}

Inorganic fertilizers are immediately available to your plants, but they are subject to leaching, a process that occurs when fertilizers are washed by rain or irrigation water below the level of plant roots. Heavy applications can burn your plants and build up toxic salt concentrations in the soil, which can create chemical imbalances. Organic fertilizer may also build up concentrations of some nutrients, but build-up of toxicity is unlikely as long as the organic material is able to fully decompose. In addition, because organic fertilizers are made from natural sources, only limited amounts of fossil fuels are used in production. This means greenhouse gas released into the atmosphere is lower in organic fertilizer production than it is in inorganic fertilizer production. Nitrification inhibitors have potential to reduce nitrate leaching and increase nitrogen use efficiency (Hazra, 2014; Hazra et al., 2014). However, measurable agronomic or environmental improvement will not be seen in all field conditions. The Controlled Release Fertilizers delivers up to 10 weeks of healthy plant growth and colour, so you can make fewer applications in a season. Less product breakage means less quick release, less surge growth and longer residual feeding. Fewer products are lost to leaching and volatilization, reducing environmental impact. Slow release fertilisers are less nitrogen "lock-off" that means we get the nitrogen we're paying for in the expected time frame. The CRF can trace elements that can be fitted into slightly soluble glasses for slow release in soil. The experiments have shown a $25-50 \%$ increase in the crop production with use of these micro nutrient glass fertilizers and the benefits can be seen for over 20 years of each addition. Micro Nutrient Glass Fertilizers release micronutrient trace chemicals in soil for balanced plant growth, over a 10-20 yr period (Hazra et al., 2014) and are not easily washed away. Both organic and inorganic fertilizers provide plants with the nutrients needed to grow healthy and strong. However, each contains different ingredients and supplies these nutrients in different ways. Organic fertilizers work over time to create a healthy growing environment, while inorganic fertilizers provide rapid nutrition. In addition to releasing nutrients, as organic fertilizers break down, they improve the structure of the soil and increase its ability to hold water and nutrients (Bokhtiar et al., 2005). Over time, organic fertilizers will make your soil — and plants - healthy and strong. Determining which is better for your plants depends largely on the needs of your plants and your preferences in terms of cost and environmental impact as "environmental friendly" fertilizers, since they allow not 
only to reduce the use of chemicals, but also to re-use agro-industrial wastes and organic residues which gave an "adding value" to these novel organo-mineral formulates (Biagio et al., 2013; Tzen et al., 2004).

\section{References}

Alloway, B. J., \& Ayers, D. C. (1999). Chemical basis of environmental pollution.

Basta, N. T., Gradwohl, R., Snethen, K. L., \& Schroder, J. L. (2001). Chemical immobilization of lead, zinc and cadmium in smaller-contaminated soils using biosolids and rock phosphate. Journal of Environmental Quality, 30, 1222-1230.

Biagio, T., Alessandra, T., Elvira, R., Maria, A., Giancarlo, R., \& Francesco I. (2013). Effects of organo-mineral glass-matrix based fertilizers on citrus Fe chlorosis. Europ. J. Agronomy, 44, 32-37.

Bokhtiar, S. M., \& Sakurai, K. (2005). Effects of organic manure and chemical fertilizer on soil fertility and productivity of plant and ratoon crops of sugarcane. Archives of Agronomy and Soil Science, 51, 325-334.

Bokhtiar, S. M., \& Sakurai, K. (2005). Effects of organic manure and chemical fertilizer on soil fertility and productivity of plant and ratoon crops of sugarcane. Archives of Agronomy and Soil Science, 51, 325-334.

Camargo, J. A., \& Alonso, A. (2006). Ecological and toxicological effects of inorganic nitrogen pollution in aquatic ecosystems: A global assessment. Environment International, 32, 831-849.

Chandra, P. K., Ghosh, K., \& Varadachari, C. (2009). A new slow-releasing iron fertilizer. Chem. Eng. Journal, 155(1-2), 451-456.

Chen, J. H. (2006). The combined use of chemical and organic fertilizers and/or Biofertilizer for crop growth and soil fertility. International Workshop on Sustained Management of the Soil-Rhizosphere System for Efficient Crop Production and Fertilizer Use (pp. 1-11). http://dx.doi.org/10.2134/jeq2001.3041222x

Hagin, J., \& Mortvedt, J. (Eds.). (n.d.). Technion, Israel Institute of Technology. Haifa. Israel.

Hara, Y. (2000). Estimation of nitrogen release from coated urea using the Richard function and investigation of the release parameters using simulation models. Soil Science and Plant Nutrition, 46, 693-701.

Hazra, G. (2013). Leaching Study of the some Lead-Iron Phosphate Simulated Nuclear Waste Glasses with Different Modifiers under Soxhlet Condition. IJAREAS, 2(12), 30-47.

Hazra, G. (2014). Slow or Controlled Release Fertilizers for the Holistic Approach to Economical and Environmental Issues: A Review. IJMER, 3(5/3), 190-208.

Hazra, G., \& Das, T. (2014). A Review on Controlled Release Advanced Glassy Fertilizer. Global Journal of Science Frontier Research: B Chemistry, 14(4), 33-44.

http://www.diffen.com/difference/Chemical_Fertilizer_vs_Organic_Fertilizer 
http://www.garden-counselor-lawn-care.com/organic-vs-non-organic-fertilizer.html

Kabata-Pendias, A., \& Pendias, H. (1993). Biochemistry of trace elements. PWN Warsaw, Polish.

Kaur, K., Kapoor, K. K., \& Gupta, A. P. (2005). Impact of organic manures with and without mineral fertilizers on soil chemical and biological properties under tropical conditions. Journal Plant Nutrition and Soil Science, 168, 117-122.

Liu, Y. L., Zhang, B., Cheng-liang, L., Feng, H., \& Velde, B. (2007). Long term fertilization influences on clay mineral composition and ammonium adsorption in rice paddy soil. Soil Sci. Soc. Am. J, 72, 1580-1590.

Madani, M. J., H., \& Mobasser, H. R. (2011). Effects of nitrogen fertilization and rice harvest height on agronomic yield indices of ratoon rice-berseem clover intercropping system. Aust. J. Crop Sci, 5(5), 566-574.

Merriam-Webster.html. (2016). Retrieved from http://www.merriam-webster.com/dictionary/fertilizer

Pansu, M., \& Gautheyrou, J. (2006). Handbook of Soil Analysis: Mineralogical, Organic and Inorganic Methods. Springer.

Prasad, R. (2009). Efficient fertilizer use: The key to food security and better environment. Journal of Tropical Agriculture, 47(1-2), 1-17.

Raicevic, S., Kaludjerivic-Radoicic, T., \& Zouboulis, A. I. (2005). In situ stabilization of toxic metals in polluted soils using phosphates: Theoretical prediction and experimental verification. Journal of Hazardous Materials, 117, 41-53. http://dx.doi.org/10.1016/j.jhazmat.2004.07.024

Roy, R. N., Finck, A., Blair, G. J., \& Tandon, H. L. S. (2006). Plant nutrition for food security: A guide for integrated nutrient management. FAO Fertilizer and Plant Nutrition Bulletin, 16.

Sava, B. A., Boroica, L., Savaa, M., Elisab, M., Vasiliub, C. I., Nastasec, F., ...Medianu, R. (2011). Potassium phosphate glasses used as agro-fertilizers with controlled solubility. Journal of Optoelectronics and Advanced Materials, 13(11-12), 1534-1541.

Shaviv, A. (2005). Controlled Release Fertilizers. IFA International Workshop on Enhanced-Efficiency Fertilizers, Frankfurt. International Fertilizer Industry Association Paris, France.

Shaviv, A., \& Mikkelsen, R. L. (1993a). Slow release fertilizers for a safer environment maintaining high agronomic efficiency. Fertilizer Research, 35, 1-12.

Shaviv, A., \& Mikkelsen, R. L. (1993b). Controlled-release fertilizers to increase efficiency of nutrient use and minimize environmental degradation-A review. Fertilizer Research, 35, 1-12.

Shaviv, A., Smadar, R., \& Zaidel, E. (2003). Model of diffusion release from polymer coated granular fertilizers. Environmental Science and Technology, 37, 2251-2256.

Shaviv, A., Zlotnikov, E., \& Zaidel, E. (1995). Mechanisms of nutrient release from controlled release fertilizers. In Proceedings, Dahlia Gredinger Memoria Internationa Workshop on Controlled Release Fertilizers.

Shoji, S. (2005). Innovative use of controlled availability fertilizers with high performance for intensive agriculture and environmental conservation. Science in China Ser. C. Life Sciences, 48, 912-920. 
Tachibana, M. (2007, 2008). Chissoasahi Fertilizer Co.. Ltd: Personal report.

Trenkel, M. E. (2010). Slow-and Controlled-Release and Stabilized Fertilizers: An Option for Enhancing Nutrient Use Efficiency in Agriculture. International Fertilizer Industry Association (IFA). Paris, France.

Trinchera, A., Allegra, M., Rea, E., Roccuzzo, G., Rinaldi, S., Sequi, P., \& Intrigliolo, F. (2011). Organo-mineral fertilisers from glass-matrix and organic biomasses: A new way to release nutrients. A novel approach to fertilisation based on plant demand. J Sci Food Agric, 13, 2386-2393.

Tzen, Z. Y., \& Chen, J. H. (2004). Evaluation the application rate of animal manure compost in a strongly acidic soil. Soil and Environment, 7, 83-96.

U.S. Environmental Protection Agency Ground Water and Drinking Water. (2006). Consumer Factsheet on: Nitrates/Nitrites. Retrieved from http://www.epa.gov/safewater/dwh/c-ioc/nitrates.html

Wacławska, I., \& Szumera, M. (2011). Interaction of glassy fertilizers and $\mathrm{Cd}^{2+}$ ions in terms of soil pollution neutralization. Natural Science, 3(8), 689-693.

World Health Organization. (2006). International Program on Chemical Safety, Environmental Health Criteria 5: Nitrates, Nitrites, and N-Nitroso Compounds. Retrieved from http://www.inchem.org/documents/pims/chemical/pimg016.htm

Young, C. C., Lai, W. A., Shen, F. T., Hung, M. H., Hung, W. S., \& Arun, A. B. (2003). Exploring the icrobial potentially to augment soil fertility in Taiwan. In Proceedings of the 6th ESAFS International Conference: Soil Management Technology on Low Productivity and Degraded Soils (pp. 25-27). 